\title{
PHYTOCHEMICAL INVESTIGATION OF TERMINALIA BELLIRICA FRUIT INSIDE
}

\author{
HAZRA K* \\ Department of Chemistry, Central Ayurveda Research Institute for Drug Development, Kolkata, West Bengal, India. \\ Email: kalyan987@gmail.com
}

Received: 28 May 2019; Revised and Accepted: 25 June 2019

\section{ABSTRACT}

Objective: The fruit of Terminalia bellirica Roxb. or Baheda (Family Combretaceae) is an extensively used herb in traditional medicines. The fruit as a whole or a part of it is used in traditional healing. Fruit has two major parts, namely, pericarp and seed, pericarp, in turn, consists of epicarp, mesocarp, and endocarp. Ayurvedic compound formulations such as Triphala and Pathyadi contain pericarp of the fruit. The present study is aiming a comparative phytochemical investigation of fruit parts such as epicarp, mesocarp, and seed along with the whole fruit.

Methods: The study included physicochemical evaluation, phytochemical screening, biochemical assay, and thin-layer chromatography profile of the inner parts of the fruit.

Results: The study shows that seeds are rich in essential oil (13.25\%), but very poor quantity of phenolics (0.65 gallic acid equivalent [GAE]) and flavonoids (0.77 quercetin equivalent [QE]) is present compared to epicarp (139.05 GAE and 141.26 QE) and mesocarp (135.23 GAE and 142.05 QE). In addition to that, qualitative phytochemical screening revealed that seeds are void of steroids and lignans.

Conclusion: The study concluded that seeds are less important in respect to the presence of secondary metabolites. It may also be concluded that mesocarp and epicarp are holding major responsibilities of therapeutic values imposed on the fruit.

Keywords: Terminalia bellirica, Fruit parts, Phytochemicals, High-performance thin-layer chromatography.

(c) 2019 The Authors. Published by Innovare Academic Sciences Pvt Ltd. This is an open access article under the CC BY license (http://creativecommons. org/licenses/by/4. 0/) DOI: http://dx.doi.org/10.22159/ajpcr.2019.v12i8.34347

\section{INTRODUCTION}

Modern drug development from the cradle of medicinal plants is the emerging trend around the globe. Herbal medicines are in a forefront of health-care tool in several countries. A report of the World Health Organization revealed that $80 \%$ of the world populations [1] in developing countries depend primarily on herbal medicines.

Terminalia bellirica is such a medicinal plant which has extensive usage as pharmaceutical and nutraceuticals. T. bellirica is found in deciduous forest throughout in India below the elevations of about $3000 \mathrm{ft}$, except in the dry and arid regions of Sind and Rajputana. It grows in upper Gangetic plains, Chota Nagpur, Bihar Orissa, West Bengal, Konkan, Deccan, and in most of South India [2]. Baheda is a tall (12-50 m) tree, with characteristic bark. Leaves are petiolate, entire, approximately $8-20 \mathrm{~cm}$ long, $7.5-15 \mathrm{~cm}$ wide, $2.15 \mathrm{~cm}$ long with petiole, alternately arranged or fascicled at the end of branches, elliptic or elliptic-obovate, surface leathery, dotted with narrow-pointed or rounded leaf-tip. Flowers arise in spikes from leaf axils, 5-15 cm long, greenish-yellow, sessile, each 5-6 mm across; each spike possesses male flowers toward upper portion and bisexual flowers toward the lower portion. Stamens are 3-4 mm long. Fruit is obovoid, $1.5-2.5 \mathrm{~cm}$ in diameter, dark brown, hard, covered with minute pale pubescence; seed stony, edible, light brown, indistinctly 5 angled [3].

Fruit of T. bellirica is widely used in Ayurvedic formulations [4] such as Triphala churna, Pathyadi churna, Phalatrikadi Kwatha churna, Avipattikara churna, and many more. To date, near about more than 151 phytochemicals have been isolated from the fruit. The presences of diversified phytochemicals make the fruit a highly potent phytomedicines. Researchers reported [5-7] antioxidant, immune modulator, analgesic, antidiabetic, antidiarrheal, antiandrogenic, antifungal, and anti-helminthic antimicrobial activity. The fruit has two major different parts (Fig. 1), pericarp and seed. Again pericarp can be subdivided into three portions such as endocarp, mesocarp, and epicarp. Endocarp is a thin papery layer which is adhered with mesocarp and difficult to separate. Mesocarp is the major portion in epicarp. Most of the Ayurvedic formulations use pericarp of the fruit as an active part. The present study is aiming in comparison of these fruit parts in respect to physicochemical, phytochemical, biochemical assay, and chromatographic profile.

\section{MATERIALS AND METHODS}

\section{Materials and reagents}

The work has been carried out using the chemicals, reagents, and solvents of Emplura grade of Merck and aluminum supported thin-layer chromatography (TLC) plates were purchased from E. Merck Pvt. Ltd. (Mumbai, India).

\section{Plant drug collection and authentication}

The matured fruits of $T$. bellirica were collected from local market of Kolkata, West Bengal, in the month of December 2018 and authenticated in the Department of Pharmacognosy, Central Ayurveda Research Institute for Drug Development, Kolkata, and deposited in the department, available for future reference.

\section{Plant samples processing and storage}

An amount of $100 \mathrm{~g}$ authenticated fruits was crushed to obtain coarse powder, kept in an airtightglass jar, and labeled as $\mathrm{F}$ (indicating whole fruit).

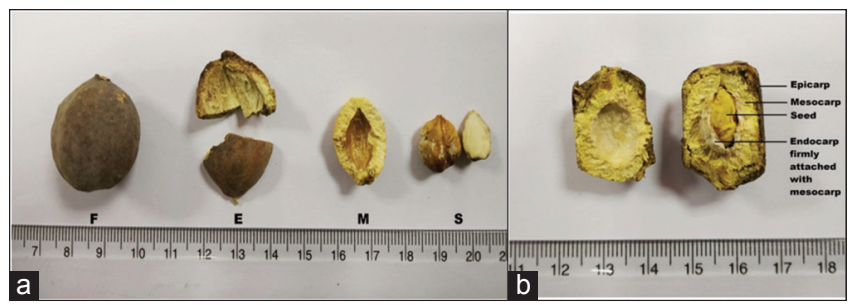

Fig. 1: (a) Whole fruit (F) with segregated parts (E: Epicarp, M: Mesocarp+endocarp, S: Seed); (b) Longitudinal section of fruit showing layers 
Table 1: Organoleptic characters

\begin{tabular}{lllll}
\hline Organoleptic characters & F & E & M & Yellowish-brown \\
\hline Color & Light brown & Light brown & Yellowish \\
Odor & Characteristics smell & Characteristics smell & Characteristics smell & No significantsmell \\
Touch & Hard and rough & Rough & Hard & Surface uneven and less hard \\
Taste & Astringent & Astringent & Astringent & Nut-like taste \\
\hline
\end{tabular}

Table 2: Physicochemical evaluations ${ }^{\mathrm{a}}$

\begin{tabular}{|c|c|c|c|c|}
\hline Parameters & $\mathbf{F}$ & $\mathbf{E}$ & $\mathbf{M}$ & $\mathbf{S}$ \\
\hline Loss on drying & $12.27 \pm 0.01$ & $13.32 \pm 0.02$ & $7.68 \pm 0.01$ & $6.52 \pm 0.01$ \\
\hline Total ash value & $3.46 \pm 0.01$ & $4.18 \pm 0.01$ & $1.23 \pm 0.02$ & $3.78 \pm 0.02$ \\
\hline Acid-insoluble ash & $0.56 \pm 0.03$ & $1.85 \pm 0.03$ & $1.41 \pm 0.04$ & $0.80 \pm 0.04$ \\
\hline Water-soluble ash & $1.91 \pm 0.01$ & $2.36 \pm 0.01$ & $1.36 \pm 0.02$ & $0.65 \pm 0.05$ \\
\hline Sulfated ash & $0.80 \pm 0.01$ & $0.93 \pm 0.01$ & $0.25 \pm 0.01$ & $0.81 \pm 0.02$ \\
\hline pH (10\% aqueous suspension) & $4.66 \pm 0.01$ & $4.56 \pm 0.02$ & $4.55 \pm 0.02$ & $5.72 \pm 0.02$ \\
\hline Alcohol-soluble extractive & $15.20 \pm 0.02$ & $20.73 \pm 0.17$ & $4.56 \pm 0.19$ & $12.50 \pm 0.18$ \\
\hline Hydroalcoholic (1: 1) extractive & $40.05 \pm 0.12$ & $32.25 \pm 0.05$ & $21.65 \pm 0.04$ & $15.41 \pm 0.04$ \\
\hline
\end{tabular}

avalues are expressed as Mean \pm S.D

Table 3: Phytochemical screening

\begin{tabular}{lllll}
\hline Phytochemical class & F & E & M & S \\
\hline Alkaloid & ++ & ++ & ++ & - \\
Flavonoid & ++ & ++ & ++ & - \\
Glycoside & ++ & ++ & ++ & $\sqrt{ }$ \\
Cardiac glycosides & + & + & + & ++ \\
Phenolic & ++ & ++ & ++ & $\sqrt{ }$ \\
Steroid & ++ & ++ & + & - \\
Terpenoid & $\sqrt{ }$ & $\sqrt{ }$ & + & ++ \\
Fatty ester & + & + & + & ++ \\
Free acid & + & + & + & + \\
Lignans & ++ & + & ++ & - \\
Tannins & ++ & ++ & ++ & $\sqrt{ }$ \\
Phlobatannins & ++ & ++ & ++ & $\sqrt{ }$ \\
Carbohydrates & ++ & ++ & ++ & $\sqrt{ }$ \\
\hline
\end{tabular}

${ }^{++}$indicates high presence, ${ }^{+}$indicates presence in moderate quantity, ${ }^{\sqrt{ } \text { indicates }}$ presence, -indicates absence of constituents

Approximately $400 \mathrm{~g}$ of fruit were broken to obtain epicarp, mesocarp (a thin papery endocarp is adhered with), and seeds. These fruit parts were sorted by handpicked and crushed separately. Segregated fruit parts were kept in three different glass jars, labeled as E (indicating epicarp), M (indicating mesocarp), and $\mathrm{S}$ (indicating seeds). Hence, four samples, namely, F, E, M, and S were obtained.

\section{Preparation of plant extract}

In this study, design different quantitative and qualitative estimation was done with the plant extracts. Hence, it was the requirement to extract the plant sample in different solvents. Therefore, the plant materials were subjected to extraction for $1 \mathrm{~h}$ in Soxhlet apparatus, separately with petroleum ether, chloroform, ethyl acetate, acetone, methanol, ethanol, water, and equivolume aqueous ethanol. In each case, $5 \mathrm{~g}$ of the plant material was extracted with $150 \mathrm{ml}$ solvent by maintaining the standard condition of extraction method as mentioned in standard [7] guidelines. Extracts were filtered and dried on evaporation and solid extracts were used for the further different phytochemical investigation and biochemical assays determination. About $1 \mathrm{~g}$ of each dried samples was extracted in chloroform:ethanol (1:1) solvent for high-performance TLC (HPTLC) profiling.

\section{Organoleptic characters}

Organoleptic properties were concluded by individual experiences through the senses such as touch, taste, sight, and smell.
Physicochemical evaluation

The physicochemical constant such as ash values, loss on drying, extractive values, and $\mathrm{pH}$ value of the plant materials were determined using coarse powder [8]. Extractability was studied with different solvents such as ethanol and water and with equivolume aqueous ethanol. Extractions were performed by conventional cold and hot extraction method [8]. pH values of samples were checked using $10 \%$ aqueous suspension.

\section{Phytochemical evaluation}

The individual dried extracts of the plant drug obtained from hexane, chloroform, acetone, ethyl acetate, methanol, ethanol, and water were used for screening the presence of secondary metabolites using standard [9] reagents and methods.

\section{Biochemical assay}

Total phenolic content was determined using Folin-Ciocalteu reagent [10] with spectrophotometry at absorption maxima $760 \mathrm{~nm}$. Gallic acid was used as standard and the phenolic content was expressed as gallic acid equivalent (GAE) in mg/gm of dry weight. Total flavonoid content was measured using ferric chloride reagent [11] and observing absorbance at $415 \mathrm{~nm}$. Estimated quantity of flavonoids was expressed as quercetin equivalents (QE) in $\mathrm{mg} / \mathrm{gm}$ of dry weight. Total tannins were determined by gravimetric method [8] using hide powder. Coarse powder materials were subjected to steam distillation [8] for determining the volatile oil content of the samples using Clevenger apparatus.

\section{HPTLC}

The extract $(2 \mu \mathrm{L})$ was applied in the form of $8 \mathrm{~mm}$ band, $15 \mathrm{~mm}$ from the bottom of a $10 \times 10 \mathrm{~cm}$ pre-activated aluminum supported precoated silica gel $60 \mathrm{~F}_{254}$ plate, with the help of ATS- 4 applicator attached to a CAMAG HPTLC system. The plate was developed in a presaturated twin trough chamber using the mobile phase as hexane:ethyl acetate:ethyl formate:formic acid $(7: 2: 0.5: 0.5, \mathrm{v} / \mathrm{v})$ to a distance of $8 \mathrm{~cm}$, dried for $5 \mathrm{~min}$ in ambient air. Images of the developed plate were captured under $254 \mathrm{~nm}$ and $366 \mathrm{~nm}$ ultraviolet (UV) light [12].

\section{RESULTS AND DISCUSSION}

\section{Organoleptic characters}

Organoleptic characters of the seed are different from rest of the fruit part. The distinguishing characters are noted in Table 1. Astringent odor indicates the high presence of tannins and phenolics, which are almost of negligible quantity in seeds attributed by the biochemical assays. 
Table 4: Biochemical assay ${ }^{\mathrm{a}}$

\begin{tabular}{|c|c|c|c|c|}
\hline Biochemical assay & $\mathbf{F}$ & $\mathbf{E}$ & $\mathbf{M}$ & $\mathbf{S}$ \\
\hline Total tannins^ & $53.74 \pm 0.11$ & $59.29 \pm 0.07$ & $59.34 \pm 0.15$ & $2.34 \pm 0.01$ \\
\hline Total phenolics ${ }^{\#}$ & $131.05 \pm 0.11$ & $139.05 \pm 0.09$ & $135.23 \pm 0.12$ & $0.65 \pm 0.02$ \\
\hline Total flavonoids $\$$ & $136.14 \pm 0.07$ & $141.26 \pm 0.11$ & $142.05 \pm 0.06$ & $0.77 \pm 0.02$ \\
\hline Volatile oils & $3.24 \pm 0.03 \%$ & $1.25 \pm 0.02 \%$ & $2.29 \pm 0.03 \%$ & $13.25 \pm 0.11 \%$ \\
\hline
\end{tabular}

aValues are expressed as Mean \pm S.D. "Values are expressed in mg of tannins in $1 \mathrm{~g}$ dried methanol extract, "Expressed as mg of gallic acid equivalent/gm of dry weighed extract, ${ }^{\$}$ Expressed as mg of quercetin equivalent/gm of dry weighed extract

Table 5: $R_{\mathrm{f}}$ values on visualization at $\mathrm{UV}-254 \mathrm{~nm}$ and $\mathrm{UV}-366 \mathrm{~nm}$

\begin{tabular}{lllll}
\hline Visualization wavelength & \multicolumn{5}{l}{ Fruit parts } & & \\
\cline { 2 - 5 } & F (whole fruit) & E (epicarp) & M (mesocarp) & S (seeds) \\
\hline $254 \mathrm{~nm}$ & $0.04,0.09,0.12,0.36$, & $0.04,0.06,0.09,0.12,0.21,0.29$, & $0.04,0.09,0.12,0.21,0.36$, & 0.04 and 0.68 \\
& $0.45,0.59,0.68,0.72$, & $0.36,0.41,0.45,0.51,0.53,0.55$, & $0.41,0.45,0.51,0.53,0.55$, & \\
$366 \mathrm{~nm}$ & and 0.79 & $0.59,0.62,0.68$, and 0.72 & $0.59,0.62,0.68$, and 0.72 & $0.02,0.31$, \\
& $0.02,0.04,0.11,0.16$, & $0.02,0.04,0.09,0.12,0.14,0.16$, & $0.02,0.04,0.09,0.12,0.14$, & 0.46, and 0.54 \\
& $0.19,0.26,0.40,0.52$, & $0.19,0.23,0.25,0.27,0.29,0.31$, & $0.16,0.19,0.23,0.25,0.27$, & \\
\hline
\end{tabular}

UV: Ultraviolet

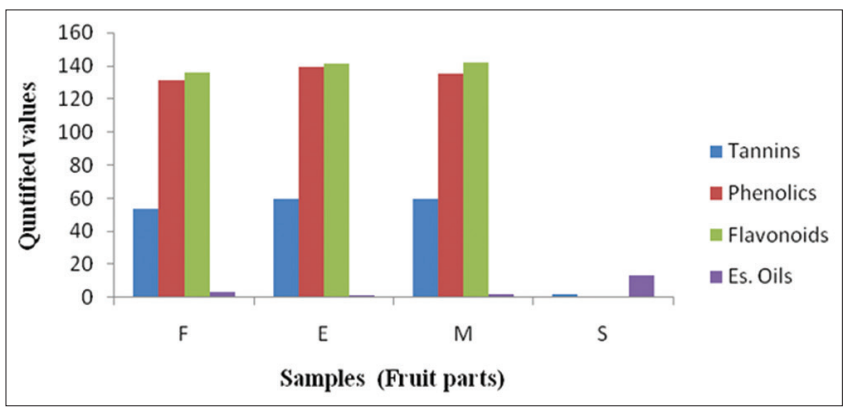

Fig. 2: Quantified values of biochemical assays

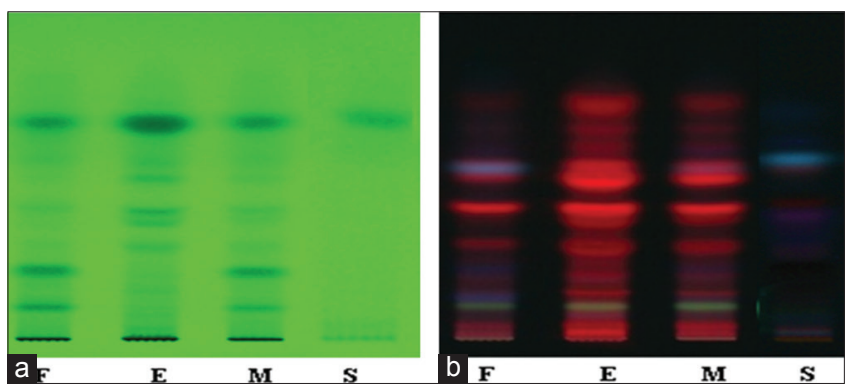

Fig. 3: High-performance thin-layer chromatography profiles of Terminalia bellirica different fruit part chloroform:ethanol extract at (a) $254 \mathrm{~nm}$, (b) $366 \mathrm{~nm}$

\section{Physicochemical evaluation}

Least water-soluble extractive value of seed indicates the presence of lesser quantity of polar phytochemicals while epicarp is having highest phytochemicals of polar nature. Other physicochemical constants are noted in Table 2.

\section{Phytochemical screening}

Major observations in phytochemical presence are noted in Table 3; it shows that seed does not contain lignans and steroids while it bears an appreciable amount of essential oil which is almost negligible in other parts. The epicarp and mesocarp contain major secondary metabolites.

Biochemical assay

The results of proximate estimation are shown in Table 4 . The seed is enriched with oils (13.25\%) and a poor quantity of tannins $(2.34 \mathrm{mg} / \mathrm{g}$ of dried plant material) is noted but almost void of phenolics ( $0.65 \mathrm{GAE})$ and flavonoids $(0.77 \mathrm{QE})$. Data obtained from the biochemical assays are shown in Table 4 and a diagram depicting the comparative quantity is represented in Fig. 2.

\section{HPTLC}

The HPTLC experimental condition was optimized using pre-activated and pre-coated TLC silica gel $60 \mathrm{~F}_{254}$ plates and different combinations of polar and non-polar solvents as the mobile phases (data not shown). The best result was obtained with hexane:ethyl acetate:ethyl formate:formic acid $(7: 2: 0.5: 0.5, \mathrm{v} / \mathrm{v})$ as the mobile phase, which showed 9, 16, 14, and 2 bands for F, E, M, and S, respectively, when visualized under UV at $254 \mathrm{~nm}$ and at $366 \mathrm{~nm}, 10,21,20$, and 4 bands for F, E, M, and S, respectively, was seen. The $R_{f}$ values of bands shown in different visualization are shown in Table 5. Pictorial representation of the bands at different visualization are given in Fig. 3a and b. The pictorial representation clearly indicates that the seed is having least quantity of phytochemicals.

\section{CONCLUSION}

The study concluded that seeds are less important in respect to the presence of secondary metabolites. The mesocarp and epicarp are holding the major responsibilities of therapeutic values imposed on the fruit.

\section{ACKNOWLEDGMENT}

Author is thankful to Director, CARIDD, Kolkata, for providing all infrastructure and Ms. Sreya Dutta, for providing assistance in authentication of plant materials.

\section{AUTHOR'S CONTRIBUTIONS}

Being the single worker, author of the present study designed the study and performed all work related to this.

\section{CONFLICTS OF INTEREST}

The author declares that he has no conflicts of interest.

\section{REFERENCES}

1. Narendra K, Khurana SM. Phytochemicals and medicinal potential of the Terminalia bellirica Roxb. (Bahera). Indian J Nat Prod Rad 2018;9:97-107.

2. Chopra RN, Nayar SL, Chopra IC. Glossary of Indian Medicinal Plants. 
$3^{\text {rd }}$ ed. New Delhi: CSIR; 1992.

3. Swati K, Mythili KJ, Arun BJ, Shailendra G, Anant VB, Amit A, et al. A pharmacognostic, phytochemical and pharmacological review of Terminalia bellerica. J Pharmacogn Phytochem 2017;6:368-76.

4. Anonymous. Ayurvedic Formulary of India. $1^{\text {st }}$ ed. New Delhi: Ministry of Health and Family Welfare, Government of India; 2001.

5. Gupta R, Singh RL, Dwivedi N. In vitro antioxidant activity and GC-MS analysis of the ethanolic extract of Terminalia bellerica Rxb. (Baheda). Int J Pharm Pharm Sci 2016;8:275-82.

6. Anrasorn S, Korkanok I. Immunomodulatory activity of an acetone extract of Terminalia bellerica Roxb fruit on the mouse immune response in vitro. Int J Pharm Pharm Sci 2014;6:274-8.

7. Deb A, Barua S, Das B. Pharmacological activities of Baheda (Terminalia bellerica): A review. J Pharmacogn Phytochem 2016;5:194-7.

8. Anonymous. Quality Control Methods for Herbal Materials. $1^{\text {st }}$ ed. Geneva, Switzerland: World Health Organization; 2011. p. 45.

9. HarpreetS,AmritaM,ArunKM.Pharmacognosticaland physicochemical analysis of Cleome viscosa L. seeds. Pharmacogn J 2017;9:372-7.

10. Tambe VD, Bhambar RS. Estimation of total phenol, tannin, alkaloid and flavonoid in Hibiscus tiliaceus Linn. wood extracts. Res Rev J Pharmacogn Phytochem 2014;2:41-7.

11. Milan SS. Total phenolic content, flavonoid concentration and antioxidant activity of Marrubium peregrinum L. Extracts. Kragujevac J Sci 2011;33:63-72.

12. Stahl E. Thin Layer Chromatography, A Laboratory Handbook. $1^{\text {st }}$ ed. New Delhi: Springer (I) Pvt. Ltd.; 2005. p. 765. 